\title{
Attitudes, Belief, and Barriers of Indonesian Oncology Nurses on Providing Assistance to Overcome Sexuality Problem
}

\author{
Yati Afiyanti \\ Department of Maternity and Women's Health Nursing, Faculty of Nursing, \\ Universitas Indonesia, Depok, Indonesia \\ Corresponding Author: Yati Afiyanti (yatikris@ui.ac.id)
}

\begin{abstract}
Background: Sexuality and problems related to sexuality have been identified as components of nursing care by the nursing profession, nurse educators, other disciplines and patients.

Purpose: This study aimed to describe the attitudes and beliefs of the Indonesian oncology nurses towards providing sexual care for the patients with cancer.

Methods: The study used a descriptive design. Using convenient sampling method, 135 oncology nurses from three hospitals in Jakarta, Indonesia participated in this study.

Results: Over $85 \%$ of the nurses believed that discussing sexuality with patients is a taboo and private issue. More than $90 \%$ of nurses understood that giving a patient permission to talk about sexual concerns is a nursing responsibility. About $73.3 \%$ nurses had beliefs that most hospitalized patients are too sick to be interested in sexuality and agreed that sexuality should be discussed if only the patient initiates it. However, more than $70 \%$ of the nurses believed that the patients expect nurses to ask about their sexual concerns.

Conclusion: This study revealed that inappropriate attitude and belief of nurses on sexuality aspect of their patients might become a barrier in facilitating the needs of cancer patients to manage the sexuality problem caused by cancer and the treatment. Nurses need to overcome those various barriers so that they can increase the quality of life of the cancer patients.
\end{abstract}

Keywords: Sexuality; attitude; barrier; oncology nurses; cancer

\section{BACKGROUND}

Living with cancer requires adaptation to many life changes of the patients. These changes comprise of the physical, psychological, social and sexual problems that might be caused by the cancer cell or its treatment (Stead, Fallowfield, Selby, \& Brown, 2007). Sexuality problems are one of the important issues that should come into our concern in providing care to the patients with cancer at any cancer trajectory. Cancer treatment may significantly affect the sexuality function of the patients with cancer. Providing and discussing information regarding sexuality problems with the patients are some important measures that should be done by the healthcare professionals, including nurses (Haesler, Bauer, \& Fetherstonhaugh, 2016; Hughes, 2009; Wilmoth \& Spinelli , 2000) 
Previous studies reported that the patients with cancer might experience various physical changes associated with the changes of vaginal structure and size. Some of these changes might threaten the patient's self-concept, body image and bring conflicts in the intimate relationship with the spouse (Afiyanti \& Milanti, 2013; Sheppard \& Ely, 2008). The patients could hardly solve this sort of problem only by themselves or with their spouses. They need assistance from the nurses to address the problems related to sexuality following the cancer diagnosis and treatment (Afiyanti \& Milanti, 2013; De Groot et al., 2005; Hughes, 2009; Jun et al., 2011).

Sexuality has been one of the important aspects of providing health care since 1970 (Bauer, Haesler, \& Fetherstonhaugh, 2015; Fisher, Bowman, \& Thomas, 2003; Tsai, 2002; Verkuyl, 2000). It has also been identified as a component of the nursing care. A holistic nursing care takes sexuality into account by reviewing the sexuality aspect, establishing the diagnosis of sexuality problem, delivering the interventions and evaluating their outcomes. Oncology nurses should play an active role in identifying and providing assistance on the management of psychosexual problems for the cancer patients. To provide effective care for the patients with cancer as well as cancer survivors, nurses should have awareness and understanding with regards to psychosexual problems.

Prior studies, however, reported that there was a range of attitudes and belief that became a barrier for nurses to discuss sexual problems with the patients, including those in Indonesia. Lack of knowledge to discuss patient's sexual problem was also identified as one of the barriers to sexuality care. Many nurses believed that sexuality is privacy and taboo to be discussed. They did not expect the patients to talk about the sexual problem with them. Some of them affirmed that there was lack of knowledge and skills to facilitate the management of their patient's sexual problems and some nurses assume that discussing the patient's sexual problem is not part of nurses' role (Butler \& Banfield, 2001; Gamel, C,Hengeveld, Davis \& Tweel, 1995; Rice, 2000; Wilmoth, 2006; Zeng, Li, Wang, Ching, \& Loke, 2011). Moreover, cultural variation in behavior, belief, and knowledge on sexuality might also pose a challenge for nurses to solve the issues of sexuality (Saunamaki, \& Engstrom, 2014; Stilos, Doyle \& Daines, 2008).

Providing education and counseling to manage problems associated with sexuality issue and sexual function are some of the recommended interventions for nurses in helping their patients to manage with a sexual problem. Counseling provided by nurses includes providing information, guidance and helping the patients with the decision making pertinent to their problems (Algier \& Kav, 2008; Butler \& Banfield, 2001; Gamel, Hengeveld \& Davis, 2000). A study conducted by Maughan and Clarke (2001) evaluated the effectiveness of counseling performed by the nurse specialists. They found that the nurse-delivered psychosexual counseling might significantly improve sexual function in a female group receiving counseling compared to those that did not have any counseling. However, some studies reported that most nurses did not routinely provide education and counseling on sexuality for their patients and the nurses often did not perform any sexuality review of nursing care in managing care for their clients. For example, Algier and Kav (2005) conducted a survey of oncology nurses and found that 
$89.5 \%$ of nurses have provided counseling on the sexual issue for less than 10 patients, and still in the same nurses' groups, only $25 \%$ of nurses who have never provided counseling on the sexual issue. In addition, various reports made by patients following hysterectomy and myocardium infarct indicated that only a few patients had received education and counseling from the nurses (Hughes, 2009; Kotronoulas, Papadopoulou \& Patiraki, 2009; Saunamaki \& Engstrom, 2014).

A range of empirical evidence associated with nursing care regarding the perception, behavior, attitudes, knowledge, and skills of the nurses in providing nursing care to perform health promotion on the sexual issue to the patients was abundantly reported in prior studies. A preliminary cross-sectional study on the role of nurses in providing intervention of health promotion on sexual issue evaluating attitudes and behavior of nurses in providing nursing care for patients with cancer associated with sexuality aspect reported that more than $67 \%$ nurses agreed that they felt comfortable when discussing sexuality with the patients and only $40 \%$ felt that there was different intensity regarding the responsibility of doing such act. Furthermore, about $91 \%$ of nurses agreed that sexual problem is one of the components in nursing care, and $89.5 \%$ of them have offered counseling on sexual issues for approximately 10 patients in the last 6 months and only $25 \%$ of them who had never offered sexual counseling for patients and/or their family (Wilson \& Williams, 1988).

While much has been written about the nurses' attitudes and belief in providing sexuality care based on American and European perspective have been extensively reported, there is little research-based information about attitudes and beliefs that become the barriers for Indonesian nurses in providing nursing care assistance to manage sexuality problems of their patient. The need for information about the attitudes and beliefs among Indonesian oncology nurses is important because the culture of Indonesian people who still feel embarrassed and uncomfortable when talking about sexuality as well as seeing it as a taboo (Endang, 2004; Nilakusmawati \& Srinandi, 2006). The next reason is that the curriculum of higher education in Indonesian nursing school does not have an educational standard to facilitate the future nurses to provide health promotion on the patients' sexual issues (Republic of Indonesia President Decree, 2012). These can impede further advance in research and application of psychosexual health care service at the level of clinical health care in Indonesia. Therefore, this study was conducted to explore the attitudes and beliefs of Oncology Indonesian nurses in assisting the management of sexuality problem experienced by the cancer patients.

\section{PURPOSE}

The aim of this study was to describe the oncology Indonesian nurses' attitudes and beliefs in order to assist cancer patient to manage with their sexuality problem.

\section{METHODS}

\section{Study design}

The present study was a descriptive study that identified attitudes and beliefs of Indonesian nurses in providing sexuality care in patients and survivors of gynecological cancer. 


\section{Setting and sample}

135 oncology nurses enrolled in this study. The nurses were determined by convenience sampling from three hospitals in Jakarta that provide cancer nursing care, in the ward and outpatient units. The inclusion criteria were nurses who had been working for at least four years in the oncology unit with the education level of at least diploma of nursing.

\section{Ethical consideration}

The ethical approval was issued by the Ethical Committee of the Faculty of Medicine, University of Indonesia. All respondents signed informed consent after the researcher had explained the study, purpose of the study, and potential risks of the study.

\section{Instrument}

Data collection was performed using questionnaires of an Inventory of Sexuality Attitudes and Beliefs Survey (SABS). Demographical data included age, sex, the level of education, the length of working period at hospital and length of working period at oncology unit. The SABS questionnaire used in the study consisted of 12 items measuring attitudes and belief in providing daily nursing care practice on sexual issues. The SABS has been previously used in earlier studies, such as to identify the attitude and belief of American nurses, (Magnan, Reynolds, \& Galvin, 2005), Swedish nurses (Saunama, Andersson, \& Engstro, 2010) and Chinese nurses (Zeng, Li, Wang, Ching, \& Loke, 2011) in discussing the patient's sexual issues in daily nursing practice. The theoretical range of the scale is 12-72 points. In the present study, the internal consistency validity of SABS was obtained with Cronbach's alpha value of 0.70 . $(n=46)$. Moreover, SABS questionnaire was translated into the Indonesian language by the first investigator and subsequently tested for its face validity by two oncology nurses who had working experiences for more than 15 years of providing nursing care for cancer patients.

\section{Data collection}

The researcher, assisted by three senior nurses from the research sites, distributed the questionnaire. Data collection was conducted in three months. All respondents filled the questionnaire and returned it within two weeks.

\section{Data analysis}

The Likert Scale for each response option of SABS was changed into the dichotomous scale, which categorized the response option into two groups, i.e. agree and disagree (Magnan et al., 2005). Descriptive and inferential statistics were used to analyze the results of the present study.

\section{RESULTS}

Table 1 showed the characteristics of nurses who participated in this study. Most nurses were female $(88.1 \%)$. About $41.5 \%$ of nurses were aged $20-30$ years old. Most of them had diploma level of education and working experiences in providing care for cancer patients. $71.9 \%$ of them had completed the Diploma in Nursing and had been working to provide care for cancer patients $(66.7 \%)$. 
Table 1. Nurses characteristics $(n=135)$

\begin{tabular}{lc}
\hline \multicolumn{1}{c}{ Characteristics } & $\%$ \\
\hline Age & \\
$20-30$ & 41.5 \\
$31-40$ & 37.8 \\
$41-50$ & 19.3 \\
$51-55$ & 1.5 \\
Sex & \\
$\quad$ Male & 11.9 \\
Female & 88.1 \\
Education Levels & 71.9 \\
$\quad$ Diploma in Nursing & 28.1 \\
Bachelor of Nursing & \\
Working Experience as a Nurse & 14.1 \\
$\quad$ < 1 year & 34.8 \\
1 - 4 year(s) & 51.1 \\
4 > years & \\
Working Experience as a Nurse at a Cancer Unit & 0.7 \\
$\quad$ < year & 32.6 \\
1 - 4 year(s) & 66.7 \\
\hline 4 years &
\end{tabular}

Table 2 summarizes the nurses' attitudes and beliefs on the sexuality care. The items of SABS were ranked by mean value. The study reported that over $85 \%$ of nurses had attitudes and beliefs that discussing sexuality with patients is a taboo and a too private issue. More than $90 \%$ of nurses had attitude and beliefs that giving a patient permission to talk about sexual concerns is a nursing responsibility. About $73.3 \%$ nurses had beliefs that most hospitalized patients are too sick to be interested in sexuality and agreed that sexuality should be discussed only if initiated by the patient. However, more than $70 \%$ the nurses believed that the patients expect nurses to ask about their sexual concerns and $85,2 \%$ the nurses understood that cancer and its treatments might affect their sexuality.

Table 2. Nurses' attitudes and beliefs towards sexuality care in cancer patients $(n=135)$

\begin{tabular}{lccc}
\hline \multicolumn{1}{c}{ Items } & $\begin{array}{c}\text { Mean } \pm \\
\text { SD }\end{array}$ & $\begin{array}{c}\text { Agree } \\
(\%)\end{array}$ & $\begin{array}{c}\text { Disagree } \\
(\%)\end{array}$ \\
\hline $\begin{array}{l}\text { I am uncomfortable talking about sexual issues } \\
\text { Most hospitalized patients are too sick to be interested in }\end{array}$ & $2.98 \pm 1.13$ & 67.4 & 32.6 \\
$\begin{array}{l}\text { sexuality } \\
\text { Whenever patients ask me a sexuality-related question, I advise }\end{array}$ & $3.10(1.20)$ & 73.3 & 26.7 \\
them to discuss it with their physician & $2.66(1.19)$ & 57.8 & 42.2 \\
$\begin{array}{l}\text { Sexuality is a too private issue to discuss with patients } \\
\text { Sexuality should be discussed only if it is initiated by the patient }\end{array}$ & $3.71(1.12)$ & 87.3 & 12.7 \\
$\begin{array}{l}\text { Discussion sexuality is essential to patient's health outcomes } \\
\text { I understand how my patients' disease and treatments might }\end{array}$ & $2.94(1.07)$ & 73.3 & 26.7 \\
affect their sexuality & $4.00(0.88)$ & 85.2 & 41.5 \\
I am more comfortable talking about sexual issues with my & & & 14.8 \\
patients than are most of the nurses with whom I work & $3.96(1.16)$ & 89.6 & 10.4 \\
I make time to discuss sexual concerns with my patients & $3.04(1.16)$ & 63.7 & 36.3 \\
\hline
\end{tabular}




\begin{tabular}{lccc}
\hline \multicolumn{1}{c}{ Items } & $\begin{array}{c}\text { Mean } \pm \\
\text { SD }\end{array}$ & $\begin{array}{c}\text { Agree } \\
(\%)\end{array}$ & $\begin{array}{c}\text { Disagree } \\
(\%)\end{array}$ \\
\hline $\begin{array}{l}\text { I feel confident in my ability to address patients' sexual } \\
\text { concerns }\end{array}$ & $3.20(1.14)$ & 68.9 & 31.1 \\
$\begin{array}{l}\text { Giving a patient permission to talk about sexual concerns is a } \\
\text { nursing responsibility }\end{array}$ & $4.21(0.94)$ & 91.1 & 8.9 \\
Patients expect nurses to ask about their sexual concerns & $3.25(1.07)$ & 75.6 & 24.4 \\
\hline
\end{tabular}

Note: Scale range for each item were 1-6.

\section{DISCUSSION}

The results of this study found that the Indonesian oncology nurses had total SABS scores ranged from 18 to $52(\mathrm{M}=38.04, \mathrm{SD}=6.19)$. The score explained that Indonesian oncology nurses had barriers in assisting cancer patients to manage with their sexual problems. The score was lower than total SABS score of Swedish nurses $(\mathrm{M}=40.7, \mathrm{SD}=$ 7.8), Chinese nurses $(\mathrm{M}=45.83, \mathrm{SD}=8.14)$, but it was higher than nurses of the United States of America $(\mathrm{M}=37.48, \mathrm{SD}=8.19)$.

This study reported that the main barrier of Indonesian nurses in providing their assistance to manage sexual problems of their patients is their strong attitude and belief $(87.3 \%)$ that sexuality is a taboo and is a very private issue to discuss with patients. The same barrier was also encountered by Chinese nurses (Zeng et al., 2011) and Taiwanese nurses (Tsai, 2004). However, it was found to be different with the Swedish nurses (Saunama et al., 2010). It might be due to the culture that Swedish nurses did not regard sexuality as a taboo. Meanwhile, in the Asia context, such as for Chinese and Indonesian people, sexuality is mostly regarded as a taboo (Khoo, 2009; Zeng et al., 2011). These barriers led to a lack of supportive care to manage sexual problems of the patients. Nonetheless, more than $85.2 \%$ of nurses believed that cancer and its treatments might affect the patient's sexuality, and $68.9 \%$ of nurses had the confidence to address patients' sexual concerns. Furthermore, over $90 \%$ of them believed that giving a patient permission to talk about sexual concerns is a nursing responsibility. Similarly, the Swedish nurses were also found to believe that they had an obligation to assist their patients to manage the sexual problems so that they could provide a comprehensive nursing care.

Another barrier experienced by Indonesian oncology nurses to address the patient's sexuality problem was that they believed the patients did not have a sexual problem. The evidence showed that about $73.3 \%$ of nurses held their attitude and belief on the fact that most hospitalized patients are too sick to be interested in sexuality and that sexual problem could only be discussed if the patients addressed them. The same attitude and belief were also shared by Chinese nurses (Zeng et al., 2011). In fact, on the other hand, the patients need information and assistance from the health care professionals, including nurses, to manage the sexuality problem, especially to cope with intimate sexual changes and altered self-image due to cancer and its treatment (Hawkins, 2009; Magnan, Reynolds, \& Galvin, 2005; Rasmusson \& Thome, 2008; Sheppard \& Ely, 2008). At this point, lack of knowledge, training, time, or the health care professionals' beliefs that sexuality is a taboo and a private issue to discuss with patients might have been barriers to initiate discussion on sexual issues (Cleary \& Hegarty, 2011; Hautamaki, Miettinen, Kellokumpu-Lehtinen, Aalto, \& Lehto, 2007; 
Haesler, Bauer, \& Fetherstonhaugh, 2016; Kotronoulas, Papadopoulou, \& Patiraki, 2009; Zeng et al., 2011). Thus, there have been unmet needs between the health care professionals and cancer patients.

The results of this study showed that the oncology nursing practice in Indonesia needs additional facilities to meet the need from patients' sexual aspect, such as a special room for consultation which provides privacy and comfortable environment both for the patients and the nurses. Comfort is an important issue in boosting the confidence to discuss the sensitive issue of sexuality. Discussion on sexuality issues with the patients should be a routine activity in the daily practice of nurses in providing nursing care; so that it may eliminate the taboo in managing the patient's sexuality problem. In addition to adequate facilities, this study indicated that the attitudes and belief of oncology nurses had become barriers to addressing sexuality problem of the cancer patients. Continuous educational program with regards to sexuality issues is necessary to overcome the barriers. Awareness is also the key to providing a comprehensive nursing care that covers sexuality issues. Moreover, nurses with expertise in sexology, sexual communication or reproduction health may also be needed for consultation as well as role models. However, a small sample size and the method of convenience sampling have become the limitations of this current study.

\section{CONCLUSION}

The results of this study showed that inappropriate attitude and belief of nurses on sexuality aspect of their patients might become a barrier in facilitating the needs of cancer patients to manage the sexuality problem caused by cancer and the treatment. Nurses need to overcome those various barriers so that they can increase the quality of life of the cancer patients. Advanced and continuous education program regarding sexuality issue and the availability of role model in providing psychosexual services are necessary for the nurses. Those programs may increase the nurses' confidence, knowledge, and skills in helping patients with their sexuality problem. Believing that sexuality is not a taboo to be discussed with their patients and having belief that cancer patients do have a sexual problem due to cancer disease and the treatment is an awareness to be raised. Hence, without waiting the patients asking for help, the nurses should professionally provide a comprehensive care including promoting health on sexuality issues of their patients before and after treatment of cancer.

\section{REFERENCES}

Afiyanti, Y., \& Milanti, A. (2013). Physical sexual and intimate relationship concerns among Indonesian cervical cancer survivors: A phenomenological study. Nursing and Health Sciences, 15(2), 151-156. doi:10.1111/nhs.12006

Algier, L., \& Kav, S. (2008). Nurses' approach to sexuality-related issues in patients receiving cancer treatments. Turkish Journal of Cancer, 56(3), 135-141.

Bauer, M., Haesler, E., Fetherstonhaugh, D., (2015). Let's talk about sex: older people's views on the recognition of sexuality and sexual health in the health-care setting. Health Expect. http://dx.doi.org/10.1111/hex.12418.

Butler, L., Banfield, V. (2001). Oncology Nurses' views on the provision of sexual health in cancer care. Journal Sex Reprod Med, 1(1), 35-39. 
Cleary, V., \& Hegarty, J. (2011). Understanding sexuality in women with gynaecological cancer. European Journal of Oncology Nursing, 15, 38-45.doi: 10.1016/j.ejon.2010.05.008

De Groot, .et. al. (2005). The psychosocial impact of cervical cancer among affected women and their partners. International Journal of Gynecological Cancer, 15(5), 918-925

Gamel, C., Hengeveld, M., \& Davis, B. (2000). Informational needs about the effects of gynaecological cancer on sexuality: a review of the literature. Journal of Clinical Nursing, 9(5), 678-688. doi:10.1046/j.1365-2702.2000.00416.x

Gamel, C., Hengeveld, M.W., Davis, B., \& Tweel, V. A. N. D. E. R. (1995). Factors that influence the provision of sexual health care by Dutch cancer nurses. International Journal Nursing Study, 32(3), 301-314.

Haesler, E., Bauer, M., \& Fetherstonhaugh, D. (2016). Sexual health and older people: A systematic review of research on the knowledge and attitudes of health professional. Nurse Education Today, 57-71.

Hautamaki, K., Miettinen, M., Kellokumpu-Lehtinen, P., Aalto, P., \& Lehto, J. (2007). Opening communication with cancer patients about sexuality-related issues. Cancer Nursing, 30(5), 399-404.

Hawkins, Y., Ussher, J., Gilbert, E., Perz, J., BPsych, M.S., \& Sundquist, K. (2009). Changes in sexuality and intimacy after the diagnosis and treatment of cancer: The experience of partners in a sexual relationship with a person with cancer. Cancer Nursing, 32(4), 271-280.

Hughes, M.K. (2009). Sexuality and cancer: The Final Frontier for Nurses. Oncology Nursing Forum, 36(5), 241-246.doi: 10.1188/09.ONF. E241-E246

Jun, E. Y., Kim, S.K., Chang, S.B., Oh, K., Kang, H.S., \& Kang, S.S. (2011). The effect of a sexual life reframing program on marital intimacy, body image, and sexual function among breast cancer survivors. Cancer Nursing, 34(2), 142-149. doi: 10.1097/NCC.0b013e3181f1ab7a

Kotronoulas, G., Papadopoulou, C., \& Patiraki, E. (2009). Nurses' knowledge, attitudes, and practices regarding provision of sexual health care in patients with cancer: critical review of the evidence. Supportive Care Cancer, 17(5), 479-501.doi: 10.1007/s00520-008-0563-5

Magnan, M. A., Reynolds, K. E., \& Galvin, E. A. (2005). Barriers to Addressing Patient Sexuality in Nursing Practice. Medsurg Nursing, 14(5), 282-290.

Rasmusson, E. M., \& Thome, B. (2008). Women's wishes and need for knowledge concerning sexuality and relationships in connection with gynecological cancer disease. Sexuality and Disability, 26, 207-218. doi: 10.1007/s11195-008-9097-5

Rice, A. M. (2000). Sexuality in cancer and palliative care 2: Exploring the issues. International Journal of Palliative Nursing, 6(9), 448-453.

Saunama, N., Andersson, M., \& Engstro, M. (2010). Discussing sexuality with patients : nurses ' attitudes and beliefs. Journal of advanced nursing, 66(6), 1308-1316. doi:10.1111/j.1365-2648.2010.05260.x

Saunamaki, N. \& Engstrom, M. (2014). Registered nurses' reflections on discussing sexuality with patients: responsibilities, doubts, and fears. J. Clin. Nurs. 23, 531-540.

Sheppard, L. A., \& Ely, S. (2008). Breast cancer and sexuality. The Breast Journal, 14(2), 176-181. 
Stead, M.L; Fallowfield, L; Selby, P; Brown, J. M. (2007). Psychosexual function and impact of gynaecological cancer. Best Practice \& Research Clinical Obstetrics and Gynaecology, 21(2), 309-320. doi:10.1016/j.bpobgyn.2006 11.008

Tsai, Y.-F. (2004). Nurses' facilitators and barriers for taking a sexual history in Taiwan. Applied Nursing Research, 17(4), 257-264. doi:10.1016/j.aprn.2004.09.011

Wilmoth, M. C. (2006). Life after cancer: What does sexuality have to do with it? Oncology Nursing Forum, 33(5), 905-910. doi: 10.1188/06.ONF.905-910

Zeng, Ying-Chun, Li, Q., Wang, N., Ching, S. S. Y., \& Loke, A. Y. (2011). Chinese Nurses' Attitudes and Beliefs Toward Sexuality Care in Cancer Patients. Cancer Nursing , 34(2), 0-6. doi:10.1097/NCC.0b013e3181f04b02 